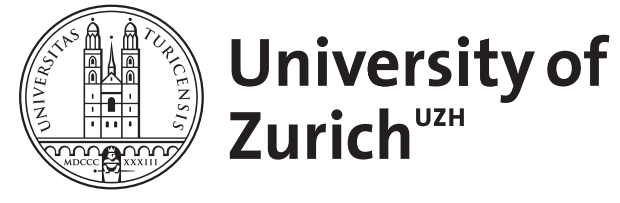

Zurich Open Repository and Archive

University of Zurich

University Library

Strickhofstrasse 39

CH-8057 Zurich

www.zora.uzh.ch

Year: 2019

\title{
Response to Al Sulais et al.
}

Greuter, Thomas ; Vavricka, Stephan R ; Scharl, Michael

DOI: https://doi.org/10.14309/ajg.0000000000000318

Posted at the Zurich Open Repository and Archive, University of Zurich

ZORA URL: https://doi.org/10.5167/uzh-178901

Journal Article

Accepted Version

Originally published at:

Greuter, Thomas; Vavricka, Stephan R; Scharl, Michael (2019). Response to Al Sulais et al. American Journal of Gastroenterology, 114(8):1346-1347.

DOI: https://doi.org/10.14309/ajg.0000000000000318 


\section{Response to Al Sulais et al.}

Thomas Greuter $M D^{1}$, Stephan R. Vavricka MD ${ }^{1,2}$, and Michael Scharl MD ${ }^{1}$

${ }^{1}$ Department of Gastroenterology and Hepatology, University Hospital Zurich, Switzerland

${ }^{2}$ Center for Gastroenterology and Hepatology, Zurich, Switzerland

We thank Dr. Eman Al Sulais and colleagues for their interest in our paper on "Malignancies in inflammatory bowel disease: Frequency, incidence and risk factors - Results from the Swiss IBD Cohort Study". The authors elegantly underscore the possible impact of family history on cancer development. ${ }^{1}$

Positive family history for cancer is a known risk factor for various cancer types in non-IBD patients. Studies have shown a two-fold increase for colorectal cancer (CRC) and a 2 to 5 -fold increase for pancreatic cancer, if a first-line relative suffered from CRC and pancreatic cancer, respectively. ${ }^{2,3}$ And many more cancer types could be mentioned here. We therefore agree that looking at this aspect would be of considerable interest. Including it as a co-variable in our multivariate models could answer the looming question whether patients with a positive family history are at particular risk if treated with immunosuppressive agents such as azathioprine. However, such analysis is not possible since family history for cancer - in contrast to family history for IBD - is not captured in the Swiss IBD cohort study (SIBDCS) questionnaires. While it might be worthwhile including such a question for future prospective cohort projects, retrospective inclusion of family history by addressing all SIBDCS patients would be largely prone to a recall bias. This would make it difficult to draw clear conclusions. It has been previously shown that reliability of self-reported family history of cancer considerably varies between case patients and controls. ${ }^{4}$ We appreciate the continued interest and insightful questions raised by Dr. Al Sulais et al. We are looking forward to upcoming cancer analyses in large IBD cohorts, where additional factors (including family history of cancer) are taken into account. This will help us to guide our patients when dealing with questions regarding IBD- and/or immunosuppression-related cancers.

\section{REFERENCES}

1. Al Sulais E, AlAmeel T. Family History Is a Risk Factor For Developing Malignancies. Am J Gastroenterol 2019 in press.

2. Leddin D, Lieberman DA, Tse F, et al. Clinical Practice Guideline on Screening for Colorectal Cancer in Individuals With a Family History of Nonhereditary Colorectal Cancer or Adenoma: The Canadian Association of Gastroenterology Banff Consensus. Gastroenterology. 2018;155(5):1325-1347.e1323.

3. Hart AR, Kennedy $\mathrm{H}$, Harvey I. Pancreatic cancer: a review of the evidence on causation. Clin Gastroenterol Hepatol. 2008;6(3):275-282.

4. Chang ET, Smedby KE, Hjalgrim H, Glimelius B, Adami HO. Reliability of self-reported family history of cancer in a large case-control study of lymphoma. J Natl Cancer Inst. 2006;98(1):61-68. 


\section{CONFLICT OF INTEREST}

Guarantor of the article: Thomas Greuter MD

Specific author contributions: All authors were involved in the concept, interpretation and drafting of this letter. All authors approved the final draft for submission.

Potential competing interests: None declared.

Financial support: This work was supported by research grants from the Swiss National Science Foundation to GR (grant No. 310030-120312), to MS (grant No. 314730_166381), to TG (grant No. P2ZHP3_168561) and to the Swiss IBD Cohort (grant no. 33CS30_148422). 